\title{
Investigations of Phytoconstituents, Antioxidant and Anti-Liver Cancer Activities of Saueda monoica Forssk Extracted by Microwave-Assisted Extraction
}

\author{
Ali A. A. Al-Shawi ${ }^{1 *}$, Mustafa Fadhil Hameed ${ }^{2}$, Nashwan Hussein Ali $^{3}$, Kawkab \\ Ali Hussein ${ }^{1}$
}

\begin{abstract}
Background: Wild edible plants are good sources for bioactive compounds, vitamins, and minerals with various applications. They can play a role in supporting the immune system and are highly beneficial as resources. Suaeda monoica Forssk is a wild edible plant that grows in Iraq and it's biological activities have not yet reported. Methods: Saueda monoica Forssk bioactive compounds were extracted by a microwave-assisted extraction method using ethanol as a solvent, and its chemical composition was analyzed by GC-MS. The biological activities were evaluated via antioxidant, anti-liver-cancer, antibacterial, and toxicity tests in vitro. Results: The results of GC-MS analysis showed that there were about 20 bioactive compounds. The most abundant compound was N,N-Dimethylglycine methyl ester, followed by 9,12,15-Octadecatrienoic acid, n-Hexadecanoic acid, and N,N-Dimethylglycine. The antioxidant activity of the ethanol extract of the plant showed a significant $\mathrm{IC}_{50}$. The extract of $S$. monoica against liver cancer cells (HCAM) showed significant toxicity. Flow cytometric analysis showed a significant induced apoptosis and cell cycle arrested at G1 phase. Conclusions: The results indicated the significance of the components of Iraqi S. monoica Forssk by MAE method as a potential food supplement in nutrition systems to prevent liver cancer and enhance the liver's defense against diseases.
\end{abstract}

Keywords: Apoptosis- cell cycle- liver cancer- natural antioxidants- Saueda monoica Forssk

Asian Pac J Cancer Prev, 21 (8), 2349-2355

\section{Introduction}

Wild edible plants are an important source of edible healthy food due to the nature of the chemical components in the fruits, leaves, roots, tubers, and rhizomes, which could have applications in medical uses and daily diet (Bharucha et al., 2010). Common wild edible plants include amaranth, asparagus, burdock, cattail, clovers, chickweed, and chicory (Tariku and Eyayo, 2017). They are reported to be used as ointments for wounds and possess antiviral activity. Various countries have been using wild edible plants species, like India, China, and some Arab and African countries (Geng et al., 2016). A number of wild edible plants grow in Iraq, but few studies have reported on their chemical compositions. One report showed the bacterial activity of 22 Iraqi wild plants (Abdulameer, 2014). One of the most famous wild edible plants in Iraq is Suaeda monoica Forssk, which belongs to the family Chenopodiaceae and grows in hypersaline soil (Iwona et al., 2014). It is used by Iraqi people in the southern region as a vegetable food and is available in vegetable shops or markets. It is believed to have health benefits, it has a good taste, and is non-toxic (Ali et al., 2018). One study investigated the phytoconstituents of a methanol extract of the wild plant in Saudi Arabia (Elsharabasy et al., 2019). People are suffering from liver diseases due to viruses, drugs, poisons, alcohol, cancer, and inherited diseases (Xiong and Guan, 2017). The long tradition of medicinal plants that have been used liver disease treatment could help to discover new plants with new bio-functions to prevent liver diseases and understand the mechanisms of action (Li et al., 2018). Wild plants could play a role in hepatic protection due their antioxidant content, which could prevent damage from reactive oxygen species (ROS) and inhibit free radical generation (Guan and He, 2015). The phyto-nutrients discovered in wild plants are growing and can be explored using different extraction methods and solvents (Traka and Mithen, 2011). Saline soils and environmental factors play a role in the chemical composition of wild plants (Ceccanti et al., 2019). In addition, their toxicity has to be evaluated, and the compositions of toxic compounds have 
to be determined to identify the toxicity of edible species and the safety of high and low-toxicity compounds like nitrites and oxalate (Yang et al., 2020). Thus, examining the toxicity of wild edible plants is very important to demonstrate the limits or high benefits of the components, while taking into consideration the development of cultivation techniques, which can also control or reduce the toxic compounds in the plants (Cornanra et al., 2018). Hence, Few reports have been used microwave-assisted extraction (MAE) for wild plants components with various solvents and compared with other extraction methods such as maceration and soxhlet extraction methods ( $\mathrm{Li}$ et al., 2017). MAE exhibited high selective efficiency for the bioactive compounds (Belwal et al., 2017). The biological properties of wild plants components extracted by MAE have not yet reported, and one report showed high antioxidant activity of three wild edible mushrooms extracted by MAE (Özyürek et al., 2014). Therefore, in the present research, used microwave-assisted extraction and ethanol solvent to investigate the bioactive compounds, antioxidant, antibacterial, and anti-liver cancer properties of S. monoica Forssk (wild edible plant).

\section{Materials and Methods}

Saueda monoica Forssk wild edible plant was collected from a farm in the southern area in Basrah province, AlSeebah district, southern of Iraq on February, 2019, as shown in (Figure 1 (b)). The wild plant was cleaned, sliced, dried under sunlight exposure for several days, ground mechanically and kept at $4{ }^{\circ} \mathrm{C}$ for further working. Microwave-assisted extraction (MAE) homemade connected with cooling bath and ethanol solvent $99 \%$ as extract solvent. The study period conducted from April, 2019 to December, 2019. All the reagents purchased from sigma Aldrich, BDH, UK and USA biological.

\section{Methods}

monoica Forssk extraction method by MAE

In a round conical flask added $5 \mathrm{~g}$ of monoica Forssk powder with $100 \mathrm{ml}$ of absolute ethanol $99 \%$ and mixed well then left for 20-30 min inside microwave-assisted extraction homemade instrument (Daewoo company, S. Korea), and started the extraction process under conditions of $1 \mathrm{~min}$ and $50^{\circ} \mathrm{C}$, as shown in (Figure 1(a)). The ethanol extract was cooled for 10-20 min and centrifuged with $15 \mathrm{~min}$ and $3000 \mathrm{rbm}$ and then filtered by whatman filter paper $20 \mu \mathrm{m}$ and kept at $4{ }^{\circ} \mathrm{C}$.

\section{GC-MS analysis method of S. monoica Forssk ethanol extract by $M A E$}

Gas chromatography mass spectrometric analysis was performed employing a GC coupled to Mass Hunter workstation software (Agilent 7890B GC with 5977A MSD, USA). Phenyl methyl siloxane $\% 5$ column, under pressure $6.0799 \mathrm{psi}$, the column temperature gradient was initiated at $40^{\circ} \mathrm{C}$ and a linear gradient was obtained by raising the temperature from 50 to $280{ }^{\circ} \mathrm{C}$ at the rate of $10^{\circ} \mathrm{C} / \mathrm{min}$. The injector was maintained at $290^{\circ} \mathrm{C}$ and 4 min solvent stopped. Helium was used as the carrier gas at a flow rate of $1 \mathrm{ml} / \mathrm{min}$. Type of injection: pulsed splitless, molecular weight test range $35-650 \mathrm{~m} / \mathrm{z}$, test rate $1562(\mathrm{~N} 2)$. The extracts were filtered through syringe filters and $1 \mu$ lof ethanol extract was injected into the GC column and analyzed according to NIST library.

\section{Antioxidant activity method}

S. monoica Forssk (MF) ethanol extract was used to evaluate antioxidant activity using DPPH (2,2-Diphenyl1-picrylhydrazyl), according to Young and his group method with some modification (Lee et al., 2013). Briefly, various concentrations of MF $(10,20,30,40,50,60,70,80)$ $\mu 1$ were added to $200 \mu 1$ of DPPH $(1 \mathrm{~mm})$ in 96 well/plate and kept in a dark place for $30 \mathrm{~min}$, and measured the absorbance at $490 \mathrm{~nm}$ by a micro-plate reader (ELISA, Asyshitech., UK), the equation (1) was used to estimate antioxidant activity $\%$ of $\mathrm{MF}$ :

Antioxidant activity $\%=\left\{1-\left[\mathrm{A}_{\mathrm{s}} / \mathrm{A}_{\mathrm{c}}\right]\right\} \times 1001$

Where: $\mathrm{A}_{\mathrm{s}}=$ absorbance of monoica Forssk +DPPH ; $\mathrm{A}_{\mathrm{c}}=$ absorbance of DPPH as control

\section{Anticancer activity Cell culture}

Liver cancer HCAM cells (Provided by Iraqi national center for cancer researches, University of AlMustansriah, Baghdad, Iraq) were maintained in $10 \mathrm{~cm}$ plate contained RPMI-1640 upplemented with 10\% FBS, 100 units $/ \mathrm{ml}$ penicillin and $100 \mu \mathrm{g} / \mathrm{ml}$ streptomycin at $37^{\circ} \mathrm{C}$ in a humidified atmosphere with $5 \% \mathrm{CO} 2$.

\section{MTT assay}

MTT assay was used to determine $\mathrm{IC}_{50}$ values of $S$. monoica Forssk on the viability of liver cancer cells HCAM as described in with some modifications (Ali et al., 2011). Briefly, liver cancer cells were plated at a density of 1x104 cells per well in 96-well plates. After $24 \mathrm{~h}$, cells were treated with $100 \mu \mathrm{l}$ of complete culture medium containing $(400,800,1000,1200,1400$ and 1800) $\mu \mathrm{g} / \mathrm{ml}$ of plant extract with an equal amount of DMSO as negative control. After incubation for $24 \mathrm{~h}$, cell viability was determined, $10 \mu \mathrm{l}$ of MTT $(5 \mathrm{mg} / \mathrm{ml})$ in phosphate buffered saline was added to each well and incubated for $4 \mathrm{~h}$. After removal of the medium, $150 \mu \mathrm{l}$ DMSO was added to each well and shaken carefully, the absorbance was recorded by micro-plate reader (ELISA, Asyshitech., UK) at a wavelength of $620 \mathrm{~nm}$, the inhibition ratio of compounds on cell growth was calculated using equation (2) (Al-Shammari et al., 2016):

Cell viability $\%=\{[\mathrm{A} 620($ control $)-\mathrm{A} 620$ (treated $)]$ / A620 (control)\} x 1002

Acridine orange / Ethidium bromide (AO/EB) staining According to Arumugam and his group method (Arumugam et al., 2019), Trypsin fersin was added to HCAM cells by trypsinization process and then added medium RPMI-1640, put a clean and sterilized slide on the planted cells dish and start planted 5,000 of HCAM cells on the slide cover and then covered tightly it by parafilm sheet for $24 \mathrm{~h}$ in the incubator $5 \% \mathrm{CO}_{2}$ and $37^{\circ} \mathrm{C}$. After 24 
$\mathrm{h}$, discard the medium and added $\mathrm{IC}_{50}$ value of $\mathrm{MF}$, then close the dish tightly and re-incubate for $24 \mathrm{~h}$, next, raised up the slide cover and put it in a clean slide and added 70 $\mu \mathrm{l}$ of $\mathrm{AO} / \mathrm{EB}$ stain, and immediately take the slide under Fluorescent microscope (Flourecent Microscope, Zeiss axiolabe, CE, Germany) to record the photos.

\section{Flow Cytometric Analysis of apoptosis}

Flow cytometric used to identity of late apoptosis according to Mohammad and his group method with some modification (Khan et al., 2012). Briefly, HCAM cells were treated with or without $\mathrm{IC}_{50}$ values of monoica Forssk extract for $24 \mathrm{~h}$. The cells were harvested, rinsed twice with PBS, and labeled with 5 uL FITC-conjugated annexin $\mathrm{V}$ according to the manufacturer's instructions. After incubation in dark for $10 \mathrm{~min}$ and then labeled with PI, the samples were immediately analyzed on a flow cytometer (Beckman Coulter, Epics XL).

\section{Flow Cytometric Analysis of Cell Cycle}

Flow cytometric used to identify G1, S and G2 gates in the cell cycle of liver cancer cells. According to Mohammad and his group method with some modification (Khan et al., 2012). HCAM cells were treated with or without $\mathrm{IC}_{50}$ values of monoica Forssk extract for $24 \mathrm{~h}$. The cells were then washed with PBS and fixed with $70 \%$ ice-cold ethanol at $4 \circ \mathrm{C}$ for overnight. After washing twice with PBS, cells were stained with a solution containing $50 \mu \mathrm{g} / \mathrm{mL}$ of PI and $100 \mu \mathrm{g} / \mathrm{mL}$ RNase A for $30 \mathrm{~min}$ in the dark at room temperature. The stained cells were analyzed by flow cytometry (Beckman Coulter, Epics XL).

\section{Statics analysis}

The experiments of DPPH and MTT methods were repeated in 4 wells. The data was analyzed by GraphPad Prism 8.1. ${ }^{*} \mathrm{P}<0.0001$ were considered as statistical significant.

\section{Results}

GC-MS analysis of S. monoica Forssk ethanol extracted by $M A E$

GC-MS is a suitable method to analysis the chemical constitute for medicinal herbs extract. Control the conditions will clarify the components. Therefore, in this research used GC-MS method to analysis chemical components of $S$. monoica Forssk ethanol extracted by MAE. the analysis results revealed about 20 bioactive compounds, as shown in Table 1. The highest peak was detected for compound 2 (Glycine, N,N-Dimethyl-, methyl ester, $\mathrm{RT}=6.415 \mathrm{~min})$, followed by compound 11 (9,12,15-Octadecatrienoic acid, RT=24.085 $\mathrm{min})$, compound 9 (n-Hexadecanoic acid, RT=22.438 min), compound 4 ( $\mathrm{N}, \mathrm{N}-$ Dimethylglycine, RT=14.906 $\mathrm{min}$ ), and others according to the NIST library.

\section{Antioxidant activity by DPPH method}

DPPH assay is a simple method for evaluating the scavenger activity of medicinal herb extracts. Here, used micro-plate reader (96 plate/well) with different concentrations of monoica extract (10-80) $\mu$ l and mixed with a constant concentration of DPPH and kept in a dark place for 20-30 min. Color changed to transparent
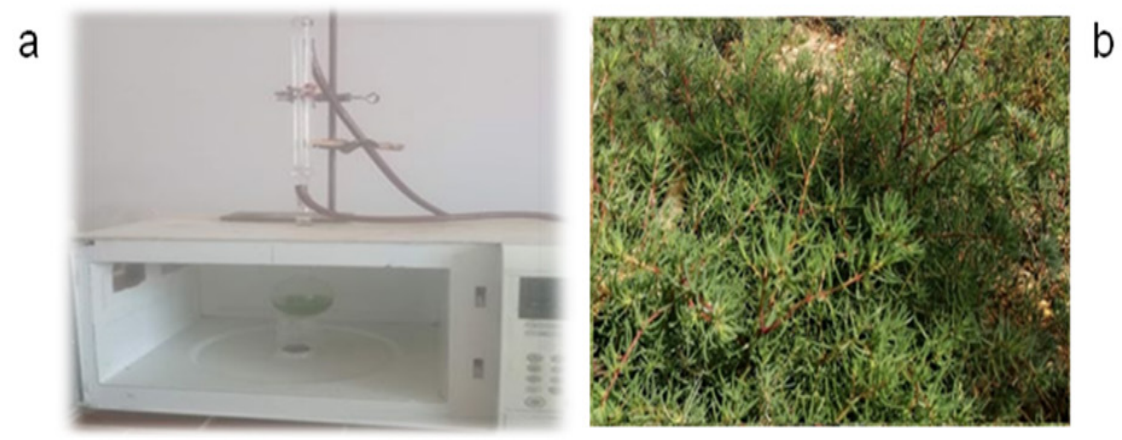

Figure 1. a) Microwave-assisted extraction (homemade). b) Iraqi S. monoica Forssk wild edible plant
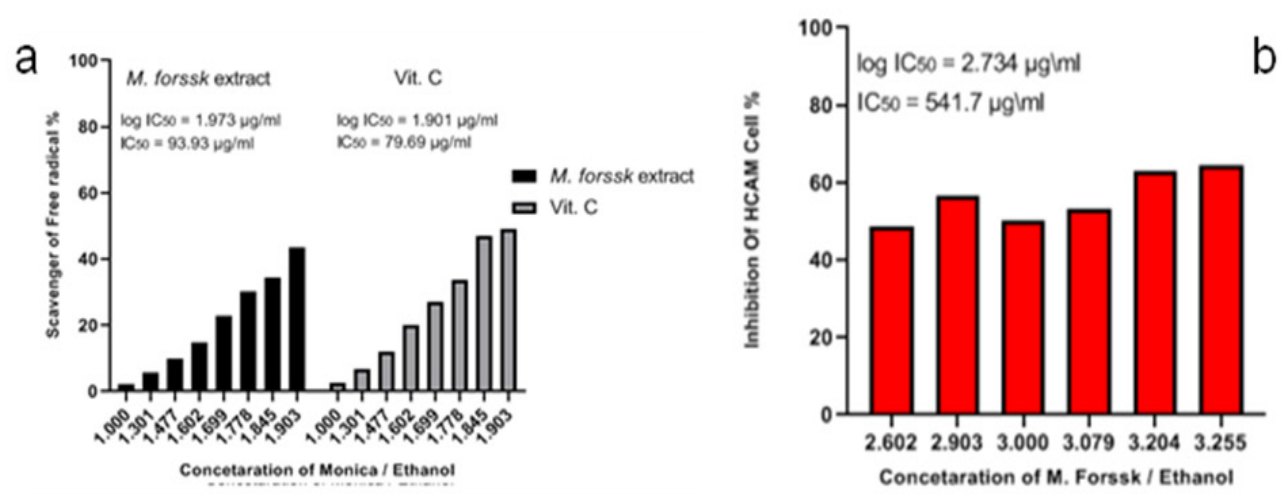

Figure 2. a) Antioxidant activity of monoica Forssk ethanol extract using DPPH method, and vitamin C as positive control; b) MTT assay of monoica Forssk ethanol extract against HCAM liver cancer cells (showed moderate action with $\mathrm{IC}_{50}$ value $=541.7 \mu \mathrm{g} / \mathrm{ml}$ ) . 
Table 1. Showed the GC-MS Chemical Compositions Analysis of monoica Forssk Ethanol Extract by MAE (Showed 8 Bioactive Compounds with High Peaks, Indicated with Red Color)

\begin{tabular}{|c|c|c|c|}
\hline No. & $\mathrm{RT}$ in $\min$ & Name of compound & Molecular Formula \\
\hline 1 & 4.434 & 1-Propanone, 1-(1-adamantyl)-3-dimethylamino- & $\mathrm{C}_{15} \mathrm{H}_{25} \mathrm{NO}$ \\
\hline 2 & 6.415 & Glycine, N,N-dimethyl-, methyl ester & $\mathrm{C}_{15} \mathrm{H}_{25} \mathrm{NO}$ \\
\hline 3 & 7.999 & Glycine, N,N-dimethyl-, ethyl ester & $\mathrm{C}_{6} \mathrm{H}_{13} \mathrm{NO}_{2}$ \\
\hline 4 & 14.906 & N,N-Dimethylglycine & $\mathrm{C}_{4} \mathrm{H}_{9} \mathrm{NO}_{2}$ \\
\hline 5 & 17.414 & $\begin{array}{l}\text { 2H-Benzo[f]oxireno[2,3-E]benzofuran- } 8(9 \mathrm{H}) \text {-one, 9-[[[2-(dimethylamino)ethyl] } \\
\text { amino]methyl]octahydro-2,5a-dimethyl- }\end{array}$ & $\mathrm{C}_{19} \mathrm{H}_{32} \mathrm{~N}_{2} \mathrm{O}_{3}$ \\
\hline 6 & 19.728 & Pterin-6-carboxylic acid & $\mathrm{C}_{7} \mathrm{H}_{5} \mathrm{~N}_{5} \mathrm{O}_{3}$ \\
\hline 7 & 21.153 & Phytol, acetate & $\mathrm{C}_{22} \mathrm{H}_{42} \mathrm{O}_{2}$ \\
\hline 8 & 21.591 & 1,2-15,16-Diepoxyhexadecane & $\mathrm{C}_{16} \mathrm{H}_{30} \mathrm{O}_{2}$ \\
\hline 9 & 22.438 & n-Hexadecanoic acid & $\mathrm{C}_{16} \mathrm{H}_{32} \mathrm{O}_{2}$ \\
\hline 10 & 23.786 & Phytol & $\mathrm{C}_{20} \mathrm{H}_{40} \mathrm{O}$ \\
\hline 11 & 24.085 & $9,12,15$-Octadecatrienoic acid & $\mathrm{C}_{18} \mathrm{H}_{30} \mathrm{O}_{2}$ \\
\hline 12 & 24.266 & Octadecanoic acid & $\mathrm{C}_{18} \mathrm{H}_{36} \mathrm{O}_{2}$ \\
\hline 13 & 24.391 & Hexadecanamide & $\mathrm{C}_{16} \mathrm{H}_{33} \mathrm{NO}$ \\
\hline 14 & 25.913 & 9-Octadecenamide, $(\mathrm{Z})-$ & $\mathrm{C}_{18} \mathrm{H}_{35} \mathrm{NO}$ \\
\hline 15 & 26.114 & Phenol, 2,2'-methylenebis[6-(1,1-dimethylethyl)-4-methyl & $\mathrm{C}_{23} \mathrm{H}_{32} \mathrm{O}_{2}$ \\
\hline 16 & 26.392 & 5,8,11,14-Eicosatetraenoic acid, methyl ester & $\mathrm{C}_{21} \mathrm{H}_{34} \mathrm{O}_{2}$ \\
\hline 17 & 27.073 & Hexadecanoic acid, 2-hydroxy-1-(hydroxymethyl)ethyl ester & $\mathrm{C}_{19} \mathrm{H}_{38} \mathrm{O}_{4}$ \\
\hline 18 & 29.991 & n-Tetracosanol-1 & $\mathrm{C}_{24} \mathrm{H}_{50} \mathrm{O}$ \\
\hline 19 & 34.133 & Stigmasterol & $\mathrm{C}_{29} \mathrm{H}_{48} \mathrm{O}$ \\
\hline 20 & 35.057 & gamma.-Sitosterol & $\mathrm{C}_{29} \mathrm{H}_{50} \mathrm{O}$ \\
\hline
\end{tabular}

indicated the scavenger ability of extract against DPPH. The results showed significant antioxidant action: the color of the test solution changed from dark violet to transparent after storing it for $30 \mathrm{~min}$. The $\mathrm{IC}_{50}$ value was $93.93 \mu \mathrm{g} / \mathrm{ml}$, which was compared with $\mathrm{IC}_{50}$ value of vitamin $\mathrm{C}(79.69 \mu \mathrm{g} / \mathrm{ml})$, as shown in (Figure 2 (a)).

Anti-liver cancer properties of S. monoica Forssk ethanol extracted by $M A E$

MTT assay and AO/EB methods

The prescreening of monoica extract showed an inhibition of growth cells ratio (40-50\%) against liver cancer cells (HCAM) by MTT assay. MTT assay used to estimation of $\mathrm{IC}_{50}$ for $24 \mathrm{~h}$. GraphPad prism software used to estimate $\mathrm{IC}_{50}$ and was equal to $541.7 \mu \mathrm{g} / \mathrm{ml}$. Furthermore, AO/EB fluorescent staining used to detect apoptosis form in the morphological changes of treated and untreated HCAM cells, as showed in as shown in (Figure 3). AO/EB method supportd by flowcytometric analysis method for estimating early apoptosis, late apoptosis, necrosis, and live cells ratios of $\mathrm{IC}_{50}$ value of monoics extract. The results of flowcytometric analysis

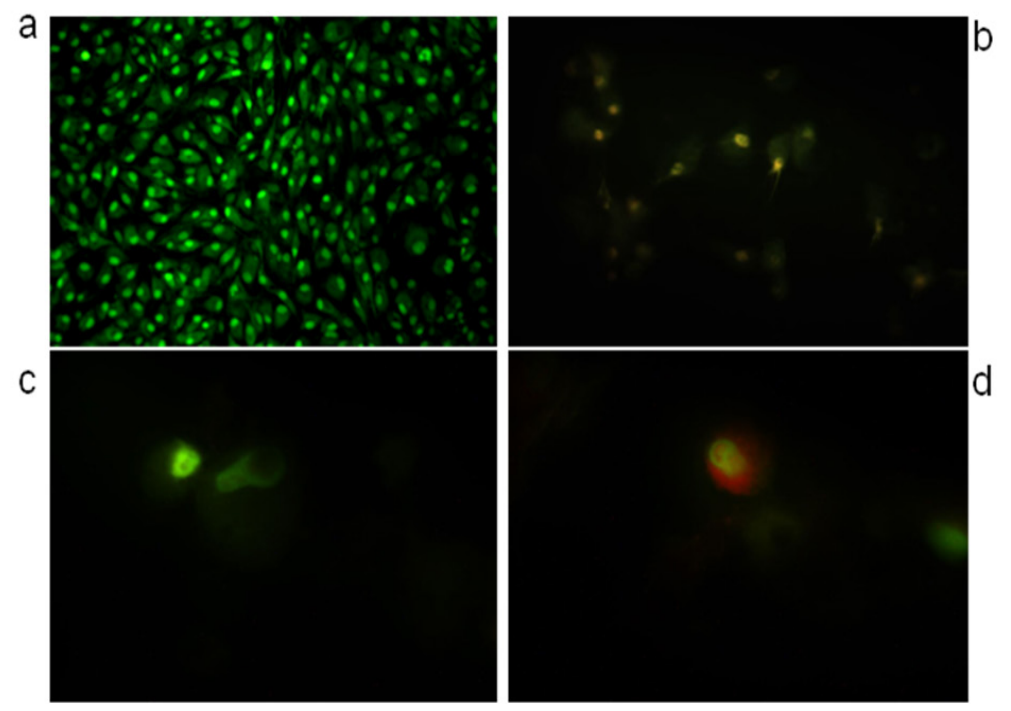

Figure 3. AO/EB Staining of monoica Forssk Extract to Detect Apoptosis and DNA Damaged: a. Untreated cells; b, Cells treated with monoica Forssk extract; c and d, Cells treated with monoica Forssk ethanol extract 

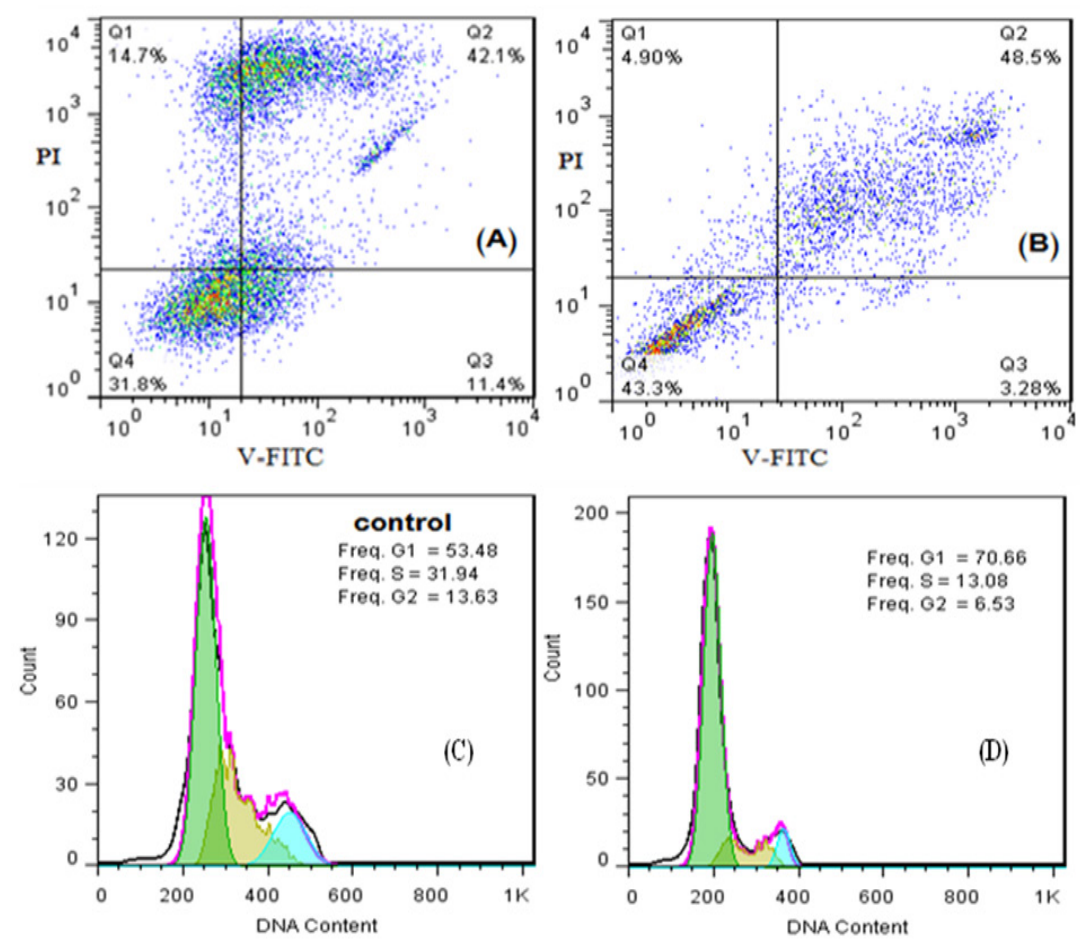

Figure 4. Flowcytometric Analysis of $\mathrm{IC}_{50}$ Value of monoica Forssk Extract Against HCAM Cancer Cells Showed: A, Cells treated with extract (Live cells $(\mathrm{Q} 4)=31.8$, early apoptosis $(\mathrm{Q} 1)=14.7$ and late apoptosis $(\mathrm{Q} 2)=42.1)$; B, Untreated cells (Live cells $(Q 4)=43.3$, early apoptosis $(Q 1)=4.9$ and late apoptosis $(Q 2)=48.5)$; C, Cell cycle arrest of cells treated with extract; D, Cell cycle arrest of untreated cells.

showed that value of early apoptosis $(\mathrm{Q} 1=4.9 \%)$, late apoptosis $(\mathrm{Q} 2=48.5 \%)$, necrosis $(\mathrm{Q} 3=3.28 \%)$ and live cells $(\mathrm{Q} 4=43.3 \%)$ compared with the control values early apoptosis $(\mathrm{Q} 1=14.7 \%)$, late apoptosis $(\mathrm{Q} 2=19.4 \%)$, necrosis $(\mathrm{Q} 3=11.4 \%)$ and live cells $(\mathrm{Q} 4=54.5 \%)$. Likewise, flowcytometric analysis used to estimate and detect the phases (G1, S, G2) in cell cycle, as shown in (Figure 4 (A,B,C,D)). S and G2 phases of cell cycle for HCAM cells treated with monoica extract showed values lower than the control, while G1 in the treated cells higher than control.

\section{Discussion}

The studies have shown that microwave-assisted extraction is an important method for the extraction of bioactive compounds because it is selective, fast, and economical, and it may replace other extraction methods to discover new natural compounds. The chemical composition of $S$. monoica Forssk extracted by microwave-assisted extraction have not yet reported. Therefore, used an ethanol extract of S. monoica Forssk prepared via MAE method in constant conditions for the first time, as shown in Figure 1 (a). The compounds contain $\mathrm{N}$ and $\mathrm{O}$ in their structures as derivatives of amino acids, fatty acids, and phenol or toxic compounds such nitrites and oxalate. These are important for human health due to their biological functions and cannot be produced by the body. Compared the results to those of Elsharabasy and his group (Elsharaby et al., 2019), who used different solvents and extraction methods for wild Saudi Arabian S. monoica Forssk. The results exhibited some similar and selective bioactive compounds. The environmental effects of the soil play an important role in the secondary metabolism of wild plant growth to produce bioactive compounds, and recommend using microwave-assisted extraction as an extraction method in future experiments for the isolation of natural molecules from medicinal plants.

The antioxidant actions of wild plants as food are important due to their functions in the body. Therefore, discovering new edible wild plants with high or moderate antioxidant activity could provide enhanced health benefits against human diseases. Carine and her group found that roots of $O$. japonica and fronds of $M$. orientalis were showed high antioxidant among all fern extracts (Carine et al., 2015). Hereby, used the DPPH method as a fast and inexpensive method with precise results to determine the antioxidant activity of the extract. The antioxidant action enhances the importance of S. monoica Forssk extracted by microwave-assisted extraction, which could possibly inhibit free radical formation in the body and prevent liver disease. Non of previous studies showed the antioxidant activity of monoica Forssk extracts and It's the first report of antioxidant evaluation of Iraqi monoica Forssk ethanol extracted by MAE method.

The studies have been showed the importance of wild edible plants against cancer diseases. Jianling and his group found that $\mathrm{C}$. sanguine extract showed significant inhibition against Hep-2 and MGC-803 tumor cells (Jiangling et al., 2013). Yiftach and his group found that Silybum marianum L. is antioxidant wild edible and enhance liver cells regeneration (Yiftach et al., 2008). Gnocchi and his group found that ethyl acetate of Brassica oleracea L. and Crithmum maritimum L. was promised in prevent growth of Hepatocellular carcinoma (Gnocchi et 
al., 2020). Mariangela and her group found that Origanum vulgare $L$. showed significant anti-proliferative against liver cancer cells HepG2 (Mariangel et al., 2015). Nasir and his group used percolation extraction method by ethanol and then used four solvent (dicholormethane, ethyl acetate, hexane and n-butanol) for extract fractions of S. monoica. Among the four solvents, dichloromethane was the most active in cells proliferation of HepG2 and it subjected for isolation the four compounds from Saudi Arabic Saueda monoica Forssk and found among them only two compounds showed a potential action against liver cancer cells HepG2 (Nasir et al., 2020).

The previous studies of Iraqi S. monoica Forssk extracted by MAE did not reported anti-liver or anticancer properties in Iraq and worldwide. In this research, the anti-liver cancer activity of Iraqi S. monoica Forssk extracted by MAE and ethanol as extraction solvent was investigated using an MTT assay. The results showed a significant toxicity against HCAM cancer cells, and the $\mathrm{IC}_{50}$ value was $541.7 \mu \mathrm{g} / \mathrm{ml}$. This value indicates a substantial potency of the bioactive compounds. To enhance the MTT assay results, AO/EB staining method was used to detect apoptosis and DNA damage by using the $\mathrm{IC}_{50}$ value of the extract in comparison with control cells (untreated cells). Apoptosis phase occurred in the HCAM cells because of the bioactive compounds function together of monoica extract, which supported the MTT assay results. MTT result combined with Nasir and his group results of Saudian monoica as anti- liver cancer cells promised the future uses of this wild herb in the traditional medicine and prevent liver diseases. Therefore, urgent further investigations of used MAE to isolate natural molecules from Iraqi S. monoica Forssk ethanol extract by MAE which responsible for the anti-liver cancer in the near future.

To our knowledge, it's a first report of apoptosis and cell cycle of S. monoica extracted by MAE against liver cancer cells HCAM. IC $_{50}$ value of monoica Forssk used to detect early and late apoptosis of HCAM cancer cells for $24 \mathrm{~h}$. The results showed late apoptosis $(\mathrm{Q} 2=48.5 \%$, higher than the control value of untreated cells $(\mathrm{Q} 2=$ $42.1 \%$,) and reduced early apoptosis value (Q1). Maybe the time of extract exposure could play a function in increasing of late apoptosis ratio in time independent. In addition, G1, S, G2 phases of HCAM cancer cells cycle identified via $\mathrm{IC}_{50}$ value of monoica Forssk extract. The results showed reduced of $\mathrm{G} 2$ and $\mathrm{S}$ ratios, while increased G1 ratio in the treated cells compared with untreated cells. Indicated that monoica Forss ethanol extracted by MAE arrested liver cancer cells cycle at G1 phase.

In conclusion the type of extraction method and solvent play a role in the selectivity of chemical compositions of wild edible plants or medicinal plants. The microwave-assisted extraction method with GC-MS analysis provided an initial library of bioactive compounds of S. monoica Forssk ethanol extract. The antioxidant and anti-liver cancer results could pave the way for the isolation of the molecules responsible for the anticancer action against HCAM liver cancer cells and mechanistic investigations. Therefore, suggested using regular daily doses of S. monoica Forssk to enhance the prevention of liver cancer and diseases.

\section{Acknowledgments}

The authors are thankful to Mr. Hasan Al-Shawi for his assistant in doing GC-MS analysis at Nahran omar location, Basrah province, Iraq. The authors are thankful to Dr. Ali Abdullateef and Dr. Ali Abood, University of Basrah, College of Education for Pure Sciences, Biology Department for their assistants in the biological activities evaluation.

\section{References}

Abdulameer A (2014). Screening for antibacterial activity of twenty two Iraqi wild plants. Glo Adv Res J Microbio, $\mathbf{3}$, 177-82.

Ali H, Barbara S, Bernadetta B (2018). Medicinal plants in Iraq. Conference: Plants in medical and natural sciences, University of Life Sciences in Lublin, The Faculty of Agrobioengineering.

Ali A, Azhar R, Muhammad K (2011). Eupatilin: A flavonoid compound isolated from the artemisia plant, induces apoptosis and G2/M phase cell cycle arrest in human melanoma A375 cells. Afr J Pharm Pharmacol, 5, 582- 8.

Al-Shammari A, Salman M, Saihood Y (2016). In vitro synergistic enhancement of Newcastle Disease Virus to 5- fluorouracil cytotoxicity against tumor cells. Biomedicines, $\mathbf{4}, 3$.

Arumugama P, Arunkumarb K, Sivakumarc L ( 2019). Anticancer effect of fucoidan on cell proliferation, cell cycle progression, genetic damage and apoptotic cell death in HepG2 cancer cells. Toxicol Rep, 6, 556-63.

Belwal T, Giri L, Bhatt I ( 2017). An improved method for extraction of nutraceutically important polyphenolics from Berberis jaeschkeana C.K. Schneid. fruits. Food Chem, 230, 657-66.

Bharucha Z, Pretty J (2010). The roles and values of wild foods in agricultural systems. Philos Trans R Soc Lond B Biol Sci, 365, 2913-26.

Carine D, Christina H, Haifang G ( 2015). Evaluation of the anti-inflammatory and antioxidative potential of four Fern species from China intended for use as food supplements. Nat Prod Commun, 10, 597-603

Ceccanti C, Landi M, Rocchetti G ( 2019). Hydroponically Grown Sanguisorba minor Scop.: Effects of Cut and Storage on Fresh-Cut Produce. Antioxidants (Basel), 8, E631.

Cornara L, Smeriglio A, Frigerio J (2018). The problem of misidentification between edible and poisonous wild plants: Reports from the Mediterranean area. Food Chem Toxicol, 119, 112-21.

Elsharabasy F, Metwally N, MahmoudA(2019). Phytoconstituents and hepatoprotective effect of SuaedA Monoica for and Suaeda Pruinosa Lange. Biomed Pharmacol J, 12.

Geng Y, Zhang Y, Ranjitkar R (2016). Traditional knowledge and it transmission of wild edibles used by the Naxi in Baidi Village, northwest Yunnan province. J Ethnobiol Ethnomed, 12, 2- 21.

Gnocchi D, Cesari G, Calabrese G ( 2020). Inhibition of Hepatocellular Carcinoma Growth by Ethyl Acetate Extracts of Apulian Brassica Oleracea L. And Crithmum Maritimum L. Plant Foods Hum Nutr, 75, 33-40.

Guan Y, He Q (2015). Plants consumption and liver health. Evid Based Complement Alternat Med, 2015, 824185.

Iwona C, Grzegorz B, Ayah A (2014). Phytochemical composition of some common coastal halophytes of the 
United Arab Emirates. Emir J Food Agric, 26, 1046- 56.

Jiangling S, Guolan G, Yulian C ( 2013). Experimental research on the in vitro antitumor effects of crataegus Sanguin. Cell Biochem Biophys, 67, 207-13.

Khan M, Yu B, Rasul A ( 2012). Jaceosidin induces apoptosis in U87 Glioblastoma cells through G2/M phase Arrest. Evid Based Complement Alternat Med, 2012, 703034.

Lee J, Kim B, Lee S ( 2013). Antioxidant activity and antiadipogenic effects of wild herbs mainly cultivated in Korea. Molecules, 18, 12937-50.

Li Y, Li S, Lin J ( 2017). Microwave-assisted extraction of natural antioxidants from the exotic Gordonia axillaris fruit: optimization and identification of phenolic compounds. Molecules, 22, E1481.

Li Q, Li J, Xu T (2018). Natural medicines use in the traditional Tibetan medical system for the treatment of liver diseases. Front Pharmacol, 9, 29.

Mariangel M, Brigida C, Francesco M ( 2015). Inhibitory effects of wild dietary plants on lipid peroxidation and on the proliferation of human cancer cells. Food Chem Toxicol, 86, 16-24.

Nasir A, Ramzi A, Mansour S (2020). Cell proliferation activity delineated by molecular docking of four new compounds isolated from the Aerial parts of Suaeda monoica Forssk. Ex J F Gmel Saudi Pharm J, 28, 172- 86.

Osada N, Kohra A, Yamaji T ( 2014). The genome landscape of the African green monkey kidney-derived vero cell line. DNA Res, 21, 673-83.

Özyürek M, Bener M, Güçlü K ( 2014). Antioxidant/antiradical properties of microwave- assisted extracts of three wild edible mushrooms. Food Chem, 157, 323-31.

Tariku B, Eyayu M (2017). Study on the diversity and use of wild edible plants bullen district Northwest Ethiopia. J Botany, 2017, Article ID 8383468.

Traka H, Mithen F (2011). Plant science and human nutrition: challenges in assessing helth promoting properties of phytochemicals. Plant Cell, 23, 2483-97.

Xiong F, Guan S (2017). Cautiously using natural medicine to treat liver problems. World J Gastroenterol, 23, 3388-95.

Yang J, Chen Y, Fu Y ( 2020). Medicinal and edible plants used by the Lhoba people in Medog County, Tibet, China. $J$ Ethnopharmacol, 249, 112430.

Yiftach V, Rivka H, Dan S (2008). The potential of milk Thistle (Silybum Marianum L.), an Israeli native, as a source of edible sprouts rich in antioxidants. Int J Food Sci Nutr, 59, $339-46$.

\section{cc) (i) (3)}

This work is licensed under a Creative Commons AttributionNon Commercial 4.0 International License. 